\title{
O impacto da crise financeira internacional de 2008 sobre a estrutura de capital das empresas de países desenvolvidos e emergentes
}

\author{
The impact of financial crisis international 2008 on corporate capital structure of \\ developing and emerging countries
}

El impacto de la crisis financiera internacional de 2008 sobre la estructura de capital de las empresas de países desarrollados y emergentes

\author{
Willian Campos Borges \\ Bacharel em Administração pela Faculdade de Economia, Administração e Contabilidade de Ribeirão \\ Preto (FEA-RP) da Universidade de São Paulo (USP) \\ Endereço: Avenida Bandeirantes, 3.900 \\ Bairro: Monte Alegre \\ CEP: 14.040-900 - Cidade: Ribeirão Preto/UF: São Paulo - Brasil \\ E-mail: wcborges@fearp.usp.br \\ Telefone: (16) 3315-4824
}

\section{Tabajara Pimenta Junior}

Doutor em Administração pela Faculdade de Economia, Administração e Contabilidade da Universidade de São Paulo (FEA/USP)

Professor Associado do Departamento de Administração da Faculdade de Economia, Administração e Contabilidade de Ribeirão Preto da Universidade de São Paulo (FEA-RP/USP)

Endereço: Avenida Bandeirantes, 3.900

Bairro: Monte Alegre

CEP: 14.040-900 - Cidade: Ribeirão Preto/UF: São Paulo - Brasil

E-mail: taba.jr@usp.br

Telefone: (16) 3315-4824

\section{Marcelo Augusto Ambrozini}

Doutor em Administração de Organizações na Universidade de São Paulo - Faculdade de Economia, Administração e Contabilidade de Ribeirão Preto (FEARP-USP)

Professor do Programa de Pós-Graduação em Controladoria e Contabilidade (PPGCC) da Faculdade de Economia, Administração e Contabilidade de Ribeirão Preto (FEARP-USP)

Endereço: Avenida Tereza Palmeira Gallon, 425 - Casa 10 - Residencial Vila do Bosque

Bairro: Jardim Itaú

CEP: 14.040-600 - Cidade: Ribeirão Preto/UF: São Paulo - Brasil

E-mail: marceloambrozini@yahoo.com.br

Telefone: (16) 9-9204-3775

\section{Lilian Beraldo Sanches Rodrigues}

Especialista em Engenharia de Produção pelo Centro Universitário de Araraquara - UNIARA

Endereço: Avenida Bandeirantes, 3.900

Bairro: Monte Alegre

CEP: 14.040-900 - Cidade: Ribeirão Preto/UF: São Paulo - Brasil

E-mail: lilianbsanches@hotmail.com

Telefone: (16) 3315-4824

Artigo recebido em 26/06/2015. Revisado por pares em 18/08/2017. Reformulado em 05/09/2017. Recomendado para publicação em 08/03/2018 por Carlos Eduardo Facin Lavarda (Editor-Chefe). Publicado em 28/03/2018. 


\section{Resumo}

Esta pesquisa teve como objetivo investigar os impactos que a crise financeira internacional de 2008 causou na estrutura de capital de empresas de todo o mundo. Utilizando uma amostra de 29.803 empresas de 48 países diferentes, foram detectados e mensurados os impactos da crise sobre seis indicadores de alavancagem, medidos para o total das empresas e também para dois grupos, um composto pelas empresas localizadas em países em desenvolvimento e outro pelas empresas de países desenvolvidos. Os resultados mostraram que houve alterações estatisticamente consistentes nas estruturas de capital das empresas entre os períodos pré e póscrise. Em síntese, houve redução nos níveis de alavancagem, resultado este que foi observado para todos os grupos analisados. Os resultados mostraram ainda que a crise afetou de forma similar as empresas de ambos os tipos de países, desenvolvidos e em desenvolvimento.

Palavras-chave: Estrutura de capital; Crise financeira; Alavancagem.

\section{Abstract}

This study aimed to investigate whether the international financial crisis of 2008 caused impacts on the capital structure of companies around the globe. Using a sample of 29,803 companies, from 48 different countries, were detected and measured the impacts of the crisis on six indicators of leverage, measured for all companies and for two groups, one composed of the companies located in emerging countries and other composed of the companies of developed countries. The results showed statistically consistent changes in capital structures of the companies between the pre-crisis and post-crisis period. There was a reduction in leverage levels, a result that was observed for all groups. The results also showed that the crisis has affected in a similar way companies of both types of countries, developed and emerging.

Keywords: Capital structure; Financial crisis; Leverage

\section{Resumen}

Este estudio tuvo como objetivo investigar los impactos que una crisis financiera internacional de 2008 causó una estructura de capital de empresas de todo el mundo. Utilizando una muestra de 29.803 empresas de 48 países diferentes, los detectores y los mensurados los impactos de la crisis sobre los indicadores de mitigación, los medidos para el total de las empresas y también para dos grupos, un compuesto de las empresas localizadas en los países en el desarrollo y otras empresas de países desarrollados. Los resultados muestran que la estabilidad se basa sistemáticamente en las estructuras de capital de las empresas entre los periodos de la crisis. En sintese, hemos reducido los niveles de apalancamiento, resultado que se observó para todos los grupos analizados. Los resultados muestran también que una crisis afecta de forma similar a las empresas de ambos tipos de países, desarrollados y en desarrollo.

Palabras clave: Estructura de capital; Crisis financeira; Apalancamiento

\section{Introdução}

Depois da publicação dos trabalhos seminais de Modigliani e Miller (1958; 1963) sobre as decisões de estrutura de capital das empresas, muitos estudos foram desenvolvidos acerca das decisões de financiamentos nas corporações. Contudo, ainda não há um consenso sobre os principais motivos para as escolhas das estruturas de capital e nem a velocidade com que mudanças nestas estruturas ocorrem.

A crise financeira internacional de 2008 foi, segundo a Conferência das Nações Unidas sobre Comércio e Desenvolvimento (UNCTAD - United Nations Conference on Trade and Development, 2010), o acontecimento mais marcante, desde a Grande Depressão de 1929, para 
O impacto da crise financeira internacional de 2008 sobre a estrutura de capital das empresas de países desenvolvidos e emergentes

as economias em todo o mundo. Os impactos desta crise superaram aqueles provocados pela Segunda Guerra Mundial, com seus desdobramentos ainda sendo refletidos mesmo após passados vários anos de seu início, se tornando um marco na história do capitalismo contemporâneo.

Apesar da amplitude global, os impactos da crise financeira internacional de 2008 não foram sentidos de maneira homogênea pelos países. As economias industriais começaram a sentir sinais de retração já no primeiro semestre de 2008, retração esta que atingiu de maneira mais contundente as economias orientadas à exportação, segundo o Bank for International Settlements - BIS (2009). Além da retração econômica, redução no PIB, dos programas de recuperação financeira e da política fiscal expansionista, no período pós-crise, as economias industriais sofreram com aquele que foi considerado, segundo o BIS (2010), o maior aumento de suas dívidas soberanas desde o período das grandes guerras, na primeira metade do século 20 .

Empiricamente, diversos estudos recentes têm demonstrado que a decisão corporativa sobre a estutura de capital é afetada durante um período de crise (e.g. ARIFF, TAUFIQ e SHAMSHER, 2008; e BHAMRA, KUEHN e STREBULAEV, 2010). Kahle e Stulz (2013) afirmam que a crise financeira de 2007-08 criou um choque na oferta de crédito disponível às empresas, mesmo nos mercados de ações, devido à migração do capital para os mercados de títulos mais seguros do mundo. Isso tornou mais oneroso o acesso ao capital por parte das organizações. Harrison e Widjaja (2014), mostraram como as graves crises financeiras podem deixar as empresas financeiramente constrangidas. Consequentemente, a maioria das empresas com restrições financeiras sofre racionamento de crédito (restrição quantitativa) no mercado de capitais, maiores custos de empréstimos (restrição de preços) e dificuldades na abertura ou renovação de uma linha de crédito. Além disso, as condições do mercado de capitais antes de uma crise financeira geralmente são mais favoráveis do que após a crise financeira. Adrian et al. (2016), por sua vez, mostraram que houve uma redução tanto no volume de captação quanto na liquidez dos títulos de corporativas nos anos que se seguiram à crise financeira de 2008, o que fez com que os investidores exigissem maiores retornos pelos ativos menos líquidos.

Complementarmente, algumas pesquisas recentes também têm demonstrado haver diferenças nos fatores determinantes da decisão de estrutura de capital nas empresas de países desenvolvidos e em desenvolvimento nos momentos de crise em relação a períodos de estabilidade financeira (e.g. DAS; DAS; LIM, 2009; DRIFFIELD; PAL, 2010; CARVALHAL; LEAL, 2013; MOKHOVA; ZINECKER, 2014; HARRISON; WIDJAJA 2014). No entanto, Harrison e Widjaja (2014), mostram que existe uma lacuna teórica a ser explorada neste campo de estudo. Os autores afirmam que, durante uma crise financeira, a quantidade de crédito canalizada para as empresas diminuiu fortemente nos países afetados pela crise, mas que a literatura ainda carece de uma confirmação pronunciada de que a crise financeira desencadeou mudanças substanciais nas escolhas da estrutura de capital das empresas.

Com base no que foi exposto até aqui e considerando-se que a crise de 2008 impactou de maneira distinta os países em todo o mundo, perguntas importantes voltaram a suscitar discussões no âmbito acadêmico e profissional, como por exemplo: como as empresas reagem à falta de crédito em períodos de crise? Quais os impactos mais relevantes das crises nas decisões de financiamento das empresas? Em períodos de crise, a alavancagem das empresas se altera? Os efeitos sobre a estrutura de capital das empresas são diferentes para as localizadas em países desenvolvidos e aquelas localizadas em países em desenvolvimento?

Motivado por estes questionamentos, o objetivo deste estudo foi investigar se a crise financeira internacional de 2008 provocou mudanças na estrutura de capital das empresas em todo o mundo, e se estas mudanças foram diferentes em função da localização das empresas, em países em desenvolvimento ou desenvolvidos. 
Para atingir esse objetivo, a amostra deste estudo foi composta por 29.803 empresas de 48 países, totalizando 210.816 pontos de observação, referentes ao período compreendido entre os anos de 2002 e 2013, contemplando uma média de 17.568 observações por ano. Com isso, é esperado que os resultados dessa pesquisa contribuam teoricamente para um amplo entendimento sobre como a crise financeira de 2008 impactou as decisões sobre a estrutura de capital das empresas em todo o mundo, tanto no conjunto total das empresas como no conjunto das empresas situadas em países desenvolvidos e nos países em desenvolvimento.

\section{Revisão da Literatura}

Crises financeiras são recorrentes no sistema capitalista, que pode ser considerado, como intrinsecamente instável. Na história recente do capitalismo ocorreram várias crises internacionais, sendo as mais severas aquelas observadas após 1975, num ambiente global sob a desregulamentação dos mercados e a ascensão do Neoliberalismo, segundo UNCTAD (2010). No final da década de 1990, diversas crises varreram os países em desenvolvimento ao redor do mundo. Países do sudeste asiático, além de Rússia, Brasil, Argentina, México e Turquia foram epicentros de crises nesse período. $\mathrm{O}$ que difere a crise bancária iniciada em 2007 no setor financeiro dos Estados Unidos e que culminou em uma crise de proporções globais em 2008 é que ela pode ser considerada a maior crise financeira da história desde a Grande Depressão em 1929.

O International Monetary Fund - IMF (2009) argumenta que as causas da crise financeira internacional de 2008 foram de origem econômica, com a quebra dos bancos dos Estados Unidos, decorrente do calote em massa de hipotecas imobiliárias ocasionado pelo segmento subprime. Além da origem econômica, essa crise teve desdobramentos morais e políticos, pois em sua essência, se tornou uma crise de confiança, o que justifica a força e rapidez com que se alastrou para a economia real. A onda de otimismo dos anos anteriores à crise, em conjunto com a grande expansão do sistema financeiro, a criação de instrumentos que aparentemente mitigavam riscos e prometiam altos retornos e a visão neoliberalista, onde a crença de que o mercado é eficiente, reduzindo ao mínimo a atuação do Estado, também contribuíram para o agravamento da intensidade e difusão da crise.

Apesar da amplitude global, os impactos da crise financeira internacional de 2008 não foram sentidos de maneira homogênea entre os países. As economias industriais começaram a sentir os primeiros sinais de retração já no primeiro semestre de 2008 , retração esta que atingiu de maneira mais contundente as economias orientadas à exportação, segundo BIS (2009). Além da retração econômica, redução no PIB, dos programas de recuperação financeira e da política fiscal expansionista, no período pós-Crise, as economias industriais sofreram com aquele que foi considerado, segundo BIS (2010), o maior aumento de suas dívidas soberanas desde o período das grandes guerras, na primeira metade do século 20.

A crise atingiu violentamente as economias em desenvolvimento no final de 2008, após a falência do Lehman Brothers Bank. Em 2009 e 2010, o epicentro da crise se deslocou para dentro da zona do Euro, onde depois permaneceu (WOLF, 2015, p. 73). Segundo BIS (2009), houve uma queda sem precedentes nas demandas de exportações, houve depreciação das taxas de câmbio em diversos países, além da queda no valor das ações das empresas e do aumento acentuado do custo de captação de financiamento externo. Com a redução da atividade real nos países industrializados, a demanda por produtos duráveis (em especial setor automotivo e de TI) e o preço das commodities apresentaram queda acentuada, com a consequente redução dos fluxos de capital estrangeiros e das exportações. 
O impacto da crise financeira internacional de 2008 sobre a estrutura de capital das empresas de países desenvolvidos e emergentes

Um dos efeitos relevantes da crise financeira internacional de 2008 foi a redução da disponibilidade de capital e do crédito. Este efeito ocorre sempre que há uma crise financeira de larga escala, o que suscita questionamentos sobre como as empresas reagem à falta de crédito em períodos de crise e quais os impactos mais relevantes nas decisões de financiamento das empresas.

No tocante aos estudos empíricos, Rajan e Zingales (1995) investigaram se os fatores que são determinantes para a escolha da estrutura de capital das empresas dos EUA eram os mesmos considerados por empresas em outros países desenvolvidos. No estudo foram utilizados dados de empresas dos países do G7. A análise de indicadores de alavancagem e mudanças estruturais revelou que as mesmas variáveis eram consideradas por empresas de todos os países. Além disso, os indicadores de alavancagem das empresas apresentaram índices muito similares.

Contrariando esses achados, Demirgüç-Kunt e Maksimovic (1998) investigaram se as estruturas de capital das empresas atuantes em países desenvolvidos e daquelas presentes em países em desenvolvimento eram diferentes e quais os possíveis fatores determinantes de uma eventual diferença. Os resultados do estudo mostraram evidências de que as estruturas de apital eram diferentes e que as decisões de financiamento de longo prazo eram influenciadas por fatores como o nível de maturidade do mercado de capitais do país e o estágio de desenvolvimento do setor bancário.

Posteriormente, Booth et al. (2001) analisaram a estrutura de capital de empresas de dez países em desenvolvimento, visando descobrir se os níveis de alavancagem diferiam significativamente daqueles assumidos por empresas de países desenvolvidos. Esse estudo também procurou investigar se os fatores que afetavam a estrutura de capital das empresas eram diferentes entre aquelas presentes nos países em desenvolvimento e as dos países desenvolvidos e, ainda, se a nacionalidade das empresas estava relacionada com o modelo da estrutura de capital adotado. Os resultados mostraram que os níveis de alavancagem não eram significativamente distintos, que os mesmos fatores eram considerados pelas empresas de ambos os grupos de países e que a nacionalidade da empresa não estava relacionada a uma determinada forma de estrutura de capital, corroborando algumas constatações de Rajan e Zingales (1995).

Em outra frente de pesquisa, Flannery e Rangan (2006) argumentaram que, fora de períodos de crise financeira, as empresas têm uma meta de longo prazo na determinação de sua estrutura de capital e convergem para esta estrutura alvo a uma velocidade em torno de $30 \%$ ao ano. Esta constatação não foi corroborada pelos resultados de Lemmon, Roberts e Zender (2008), que estudaram o comportamento de empresas não financeiras, durante o período de 1965 a 2003, e encontraram evidências de que as companhias tendem a manter suas decisões de alavancagem estáveis ao longo do tempo. Cabe ressaltar que esse estudo contemplou um horizonte de 20 anos em que houve a ocorrência de crises.

Por sua vez, Das, Das e Lim (2009) analisaram empresas de Singapura durante a crise financeira internacional, que ficou conhecida como Crise Asiática de 1997, e descobriram que as empresas tendem a optar por endividamento em ambientes mais dinâmicos. Um estudo complementar, o de Driffield e Pal (2010), verificou a evolução da estrutura de capital de empresas não financeiras situadas no Leste Asiático, em um período anterior e posterior à Crise Asiática. Foram encontradas evidências de que as empresas mudaram sua estrutura de capital e as alterações ocorreram em diferentes velocidades, que por sua vez, estava diretamente relacionada com a intensidade do impacto da crise no país.

Em um estudo mais abrangente, Campello, Graham e Harvey (2010) investigaram as decisões de financiamento tomadas por 1.050 empresas em 39 países diferentes da América do Norte, Europa e Ásia, e detectaram que empresas com maiores restrições financeiras 
planejavam cortes mais profundos no orçamento de investimento (mesmo projetos com VPL positivos), tecnologia, marketing e empregos em comparação com empresas sem restrições. Além disso, empresas com restrições tiveram que utilizar uma porção maior de seu caixa, cortar a distribuição de dividendos e se endividaram mais, na medida em que utilizaram a capacidade máxima de suas linhas de financiamento com medo de que maiores restrições futuras de crédito. Este comportamento não foi observado em empresas sem restrições.

Ao analisar os determinantes da estrutura de capital de 40 países, Kayo e Kimura (2011), encontraram evidências de que os fatores mais importantes para a determinação da estrutura de capital eram relacionados a variação da estrutura no tempo e nas características específicas da empresa (lucratividade e tamanho) em detrimento de características macroeconômicas dos países e do setor de atividade da empresa. Este resultado não é aderente aos de estudos anteriores, como o de Demirgüç-Kunt e Maksimovic (1998), em que as características macroeconômicas mostraram ter um importante papel na determinação da estrutura de capital das empresas. Estudos posteriores, como o de Mokhova e Zinecker (2014), também obtiveram resultados divergentes aos de Kayo e Kimura (2011), ao mostrar que a estrutura de capital das empresas tem sua composição afetada pelas condições macroeconômicas e especificidades dos países.

Garcia-Appendini e Montoriol-Garriga (2013) estudaram o impacto da crise financeira internacional de 2008 sobre a situação de liquidez das empresas e encontraram evidências de que, aos primeiros sinais da crise, as empresas com menor acesso a crédito bancário passaram a utilizar em maior grau as fontes de financiamento operacionais. No mesmo ano, Carvalhal e Leal (2013) investigaram os fatores determinantes da composição do endividamento de empresas brasileiras antes e durante a crise dos subprimes. As principais constatações dos autores foram: (i) o uso de Eurobonds pelas empresas brasileiras flutua de acordo com a variação cambial e ainda é pequeno considerando o tamanho da economia brasileira; (ii) o financiamento de curto prazo e os empréstimos bancários, nacionais e estrangeiros, diminuíram em 2008 e foram substituídos por títulos de dívida nacionais e internacionais, além da emissão de American Depository Receipts (ADRs); (iii) as empresas com acionistas estrangeiros recorreram mais frequentemente aos mercados de capitais estrangeiros; (iv) as empresas que empregam dívida internacional tendem a usar todas as outras fontes de financiamento com maior frequência e (v) os empréstimos bancários internacionais podem ser o primeiro passo para reduzir as restrições internacionais de financiamento às empresas brasileiras.

Harrison e Widjaja (2014), observaram, em um estudo que abrangeu 331 empresas não financeiras listadas no índice Standard\&Poor's 500, que durante um período de crise, os fatores que exercem influência sobre as decisões de endividamento das empresas são modificados. Os pesquisadores observaram que o coeficiente de tangibilidade dos ativos e o índice book-tomarket exerceram uma influência maior nas decisões de estrutura de capital das empresas durante a crise de 2008 do que antes da crise. Nesse estudo, os autores utilizaram os anos de 2004-2007 como período anterior à crise financeira e 2008-2011 como o período posterior a crise. Foi constatado ainda que os índices de rentabilidade exerceram menor influência sobre a escolha da estrutura do capital durante o período de crise do que antes da crise. Curiosamente, os autores observaram que, durante a crise, o tamanho da empresa esteve negativamente correlacionado com o seu endividamento, o que foi exatamente o oposto da situação observada no período anterior à crise. Outra conclusão dos autores foi a de que, durante todo o período do estudo (2004 a 2011), nenhuma das teorias de estrutura de capital analisadas (trade-off, pecking order e market timing) foi capaz de explicar completamente o padrão de endividamento observado no estudo. 
O impacto da crise financeira internacional de 2008 sobre a estrutura de capital das empresas de países desenvolvidos e emergentes

Em um estudo realizado na Europa, Iqbal e Kume (2014) examinaram o impacto da crise de 2008 na estrutura de capital das empresas dos três países europeus mais desenvolvidos - Inglaterra, França e Alemanha - no período pré-crise (2006 e 2007), crise (2008-2009) e póscrise (2010-2011). A amostra abrangeu 1.748 empresas inglesas, 1.622 empresas francesas e 1.345 empresas alemãs. Os resultados indicaram que, na média, os níveis de endividamento das empresas inglesas e alemãs aumentam do período anterior à crise (2006-2007) para período de crise (2008-2009). No entanto, esses índices diminuíram no período após a crise (2010 -2011). Particularmente, a elevação do endividamento no período de crise foi mais fortemente observada para as empresas que possuíam uma baixa alavancagem financeira antes da crise. Similarmente, a diminuição do endividamento após a crise foi mais claramente observada para as empresas que experimentaram um maior nível de dívida no período da crise.

Por sua vez, Dang, Kim e Shin (2014) estudaram o impacto da crise financeira internacional de 2008 sobre as estruturas de capital das empresas dos EUA. Os autores dessa pesquisa trabalharam com dados referentes ao período de 2002 a 2012 e investigaram a velocidade com que as estruturas foram ajustadas para arcar com o novo ambiente. Foram encontradas evidências empíricas significativas de que a crise teve um impacto negativo na velocidade de ajuste, e que os impactos foram mais severos nas empresas com maior restrição financeira.

Mais recentemente, Alves e Francisco (2015) analisaram o impacto das três crises financeiras do século XXI - a crise das empresas Ponto-com, a crise dos empréstimos subprime e a crise da dívida soberana europeia - sobre a estrutura de capital das empresas de 43 países no período de 2000 a 2011. Particularmente, os autores incluíram na pesquisa algumas variáveis institucionais dos países analisados. No entanto, os resultados foram inconclusivos quanto à interação entre as variáveis institucionais - principalmente o índice de percepção da corrupção, o desenvolvimento do mercado e o desenvolvimento bancário - e o impacto que as crises financeiras causam nas opções de alavancagem e financiamento das firmas. Nesta pesquisa, os autores testaram dois modelos de regressão linear múltiplo. Um contendo o nível de endividamento como variável dependente e o outro contendo a maturidade da dívida como variável dependente. A principal constatação do estudo foi que as empresas aumentaram significativamente seus níveis de alavancagem durante os períodos de crise financeira, momento no qual as dívidas de longo prazo foram substituídas por dívidas de curto prazo. Esses dois efeitos foram sentidos inequivocamente após a crise dos subprimes e a crise da dívida soberana europeia. No entanto, a redução da maturidade da dívida corporativa foi sentida mais fortemente nas empresas dos países da zona do Euro.

Em síntese, vários estudos mostraram que as estruturas de capital das empresas podem ser afetadas pelo comportamento de variáveis macroeconômicas e por características dos países em que atuam. Portanto é esperado que crises financeiras de escala global, como a de 2008, afetem as decisões de financiamento das empresas, e que os efeitos podem ser diferentes de acordo com as características dos países. Daí a motivação para a investigação proposta neste estudo.

\section{Método de Pesquisa}

Segundo classificação metodológica apresentada por Richardson (1999, p. 70), este estudo pode ser caracterizado como uma pesquisa quantitativa. Para o autor, o método quantitativo caracteriza-se pelo emprego da quantificação tanto nas modalidades de coleta de informações quanto no tratamento delas por meio de técnicas estatísticas. Com base no seu objetivo geral, esta pesquisa pode ser classificada como descritiva. Para Gil (2002, p. 42), as pesquisas descritivas têm como objetivo primordial a descrição e o estabelecimento de relações 
entre variáveis. No caso dessa pesquisa, a relação estudada será entre as variáveis crise financeira e endividamento das companhias da amostragem analisada. Por fim, este estudo também se caracteriza como uma pesquisa longitudinal, uma vez que as amostras permanecem as mesmas ao longo do tempo, tendo somente seus valores sofrendo alterações.

Com relação aos dados utilizados nesta pesquisa, eles podem ser considerados secundários, uma vez que foram extraídos das demonstrações contábeis das empresas da amostra que foram divulgadas para finalidades que não os desta investigação. As variáveis necessárias para a realização dos testes empíricos foram coletadas da Thomson One Banker Data Base, extraídas a partir dos relatórios financeiros de 29.803 empresas de 48 países. Esses países foram divididos em países desenvolvidos em desenvolvimento segundo a classificação do Fundo Monetário Internacional (FMI), um órgão especial da Organização das Nações Unidas (ONU) que tem 186 países membros. O FMI segmenta os países em apenas dois grupos: o dos países desenvolvidos e o dos países em desenvolvimento. O grupo dos países desenvolvidos é composto por sete países (EUA, Canadá, Japão, Itália, França, Reino Unido e Alemanha) e é conhecido pela denominação "G7", ou grupo dos sete países mais ricos do mundo. Todo os demais países do mundo são considerados países em desenvolvimento. (IMF, 2015).

Ao todo foram levantados 210.816 pontos de observação, referentes ao período entre os anos de 2002 e 2013, contemplando uma média de 17.568 observações por ano. A justificativa para a escolha desse período deve-se ao fato de se objetivar analisar, nesta pesquisa, uma quantidade de anos iguais para cada o intervalo antes da crise e após a crise de 2008-2009 (5 anos antes e 5 anos após), a exemplo do que foi feito em pesquisas anteriores, tais como Iqbal e Kume (2014) e Harrison e Widjaja (2014). Assim, o período considerado no estudo, de 2002 a 2013, foi dividido em três intervalos denominados: Pré-Crise (2002 - 2006), Crise (2007 2008) e Pós-Crise (2009 - 2013).

Foram calculadas as médias anuais de seis indicadores de alavancagem para o conjunto das empresas, que foram denominados: Endividamento Oneroso, Relação Dívida/PL, Endividamento Líquido 1, Endividamento Líquido 2, Endividamento de Longo Prazo, e Endividamento a Mercado. Estes indicadores foram calculados com as seguintes relações:

EndividamentoOneroso $=$ PassivoFinanceiro $/$ PassivoTotal

Relação Dívida $/ P L=$ PassivoFinanceiro/PatrimônioLíquido

EndividamentoLíquido1 $=($ PassivoFinanceiro - Disponível $) /$ PatrimônioLíquido

Endiv. Líquido2 $=($ PassivoFinanceiro - FluxodeCaixa $) /$ PatrimônioLíquido

EndividamentodeLongoPrazo $=$ PassivodeLongoPrazo $/$ PassivoTotal

Endiv.aMercado $=\frac{\text { PassivoFinanceiroTotal }}{(\text { PassivoFinanceiroTotal }+ \text { ValordeMercadodaEmpresa })}$

Para cada uma das séries de médias de indicadores de alavancagem foi aplicado o Teste de Normalidade de Kolgomorov-Smirnov, com nível de confiança estatística de 95\%. Em função da rejeição da hipótese de normalidade da distribuição das séries de indicadores de alavancagem, foi aplicado o teste de hipóteses de Mann-Whitney para as seguintes hipóteses: 
$\mathrm{H}_{0,1}$ : As medianas dos indicadores de alavancagem são estatisticamente iguais nos períodos Pré-Crise e Pós-Crise.

H1,1: As medianas dos indicadores de alavancagem são estatisticamente diferentes nos períodos Pré-Crise e Pós-Crise.

Essa hipótese de nulidade foi fundamentada e formulada com base em alguns estudos recentes desenvolvidos sobre esse tema, conforme apresentados anteriormente na revisão da literatura deste artigo, especialmente nos estudos de Iqbal e Kume (2014) e Alves e Francisco (2015). Em suma, essas pesquisas mostraram que os níveis de endividamento das empresas tendem a ser afetados durante o período de crise, mas que retornam aos patamares anteriores à crise tão logo termine a crise.

Em seguida, as empresas foram separadas em dois grupos, em função da sua localização: grupo dos países desenvolvidos e grupo dos países em desenvolvimento. As médias anuais dos indicadores de alavancagem foram novamente calculadas e reorganizadas nos três períodos de Pré-Crise, Crise e Pós-Crise.

Para cada uma das séries de médias de indicadores de alavancagem, separadas para o grupo de empresas de países desenvolvidos e o grupo de empresas de países em desenvolvimento, foi aplicado o Teste de Normalidade de Kolgomorov-Smirnov, com nível de confiança estatística de $95 \%$. Em função da rejeição da hipótese de normalidade da distribuição das séries de indicadores de alavancagem, foi aplicado o teste de hipóteses de Mann-Whitney para as seguintes hipóteses:

$\mathrm{H}_{0,2}$ : As medianas dos indicadores de alavancagem das empresas dos países desenvolvidos são estatisticamente iguais nos períodos Pré-Crise e Pós-Crise.

H1,2: As medianas dos indicadores de alavancagem das empresas dos países desenvolvidos são estatisticamente diferentes nos períodos Pré-Crise e Pós-Crise.

$\mathrm{H}_{0,3}$ : As medianas dos indicadores de alavancagem das empresas dos países em desenvolvimento são estatisticamente iguais nos períodos Pré-Crise e Pós-Crise.

H1,3: As medianas dos indicadores de alavancagem das empresas dos países em desenvolvimento são estatisticamente diferentes nos períodos Pré-Crise e Pós-Crise.

Essas hipóteses de nulidade foram formuladas com base no estudo Booth et al. (2001) sobre os fatores determinantes da estrutura de capital nos países desenvolvidos e em desenvolvimento, apresentado na revisão da literatura. Conforme apresentado anteriormente, esse estudo mostrou não haver diferenças significativas entre os índices de endividamento e os fatores determinantes na decisão da estrutura de capital entre as empresas desses dois conjuntos de países.

\section{Análise dos Resultados}

A Tabela 1 apresenta as médias anuais dos indicadores de alavancagem calculados para o conjunto total das 29.803 empresas dos 48 países analisados.

Foi aplicado aos dados desta pesquisa o Teste de Normalidade de Kolgomorov-Smirnov para os indicadores do conjunto total das empresas, com nível de confiança estatística de 95\%. A hipótese de normalidade da distribuição das séries de indicadores de alavancagem foi rejeitada para todos os 6 indicadores de endividamento. 
Tabela 1 - Médias anuais dos indicadores de alavancagem para o total das empresas

\begin{tabular}{lcccccc}
\hline Conjunto Total das Empresas & \multicolumn{1}{l}{} \\
\hline \hline Período & $\begin{array}{c}\text { Endivida- } \\
\text { mento } \\
\text { Oneroso }\end{array}$ & $\begin{array}{c}\text { Relação } \\
\text { Dívida/PL }\end{array}$ & $\begin{array}{c}\text { Endivida- } \\
\text { mento } \\
\text { Líquido 1 }\end{array}$ & $\begin{array}{c}\text { Endivida- } \\
\text { mento } \\
\text { Líquido 2 }\end{array}$ & $\begin{array}{c}\text { Endivida- } \\
\text { mento de } \\
\text { Longo Prazo }\end{array}$ & $\begin{array}{c}\text { Endivida- } \\
\text { mento a } \\
\text { Mercado }\end{array}$ \\
\hline Pré-Crise & $\mathbf{0 , 2 5 0 1}$ & $\mathbf{0 , 6 5 4 3}$ & $\mathbf{0 , 2 6 3 2}$ & $\mathbf{0 , 2 3 4 3}$ & $\mathbf{0 , 5 1 6 8}$ & $\mathbf{0 . 3 0 9 4}$ \\
\hline 2002 & 0,2595 & 0,6636 & 0,2684 & 0,2422 & 0,5075 & 0.3482 \\
\hline \hline 2003 & 0,2573 & 0,6737 & 0,2688 & 0,2412 & 0,5114 & 0.3293 \\
\hline \hline 2004 & 0,2488 & 0,6518 & 0,2612 & 0,2343 & 0,5190 & 0.3064 \\
\hline \hline 2005 & 0,2445 & 0,6448 & 0,2580 & 0,2290 & 0,5205 & 0.2988 \\
\hline \hline Crise & 0,2441 & 0,6439 & 0,2615 & 0,2287 & 0,5227 & 0.2788 \\
\hline 2007 & $\mathbf{0 , 2 4 7 7}$ & $\mathbf{0 , 6 5 3 4}$ & $\mathbf{0 , 2 6 6 0}$ & $\mathbf{0 , 2 3 2 2}$ & $\mathbf{0 , 5 1 5 9}$ & $\mathbf{0 . 3 1 8 4}$ \\
\hline \hline 2008 & 0,2402 & 0,6374 & 0,2616 & 0,2277 & 0,5212 & 0.2718 \\
\hline Pós-Crise & 0,2549 & 0,6689 & 0,2702 & 0,2366 & 0,5107 & 0.3616 \\
\hline 2009 & $\mathbf{0 , 2 4 4 6}$ & $\mathbf{0 , 6 3 3 2}$ & $\mathbf{0 , 2 6 4 9}$ & $\mathbf{0 , 2 3 2 4}$ & $\mathbf{0 , 5 2 2 5}$ & $\mathbf{0 . 3 2 1 4}$ \\
\hline \hline 2010 & 0,2532 & 0,6501 & 0,2692 & 0,2371 & 0,5194 & 0.3366 \\
\hline \hline 2011 & 0,2362 & 0,6193 & 0,2633 & 0,2295 & 0,5242 & 0.3025 \\
\hline \hline 2012 & 0,2422 & 0,6313 & 0,2637 & 0,2298 & 0,5191 & 0.3275 \\
\hline \hline 2013 & 0,2455 & 0,6340 & 0,2646 & 0,2321 & 0,5204 & 0.3278 \\
\hline Média Geral & 0,2459 & 0,6315 & 0,2642 & 0,2335 & 0,5296 & 0.3126 \\
\hline \hline
\end{tabular}

Fonte: Elaboração própria

Com base nisso, foi então aplicado o Teste Não-Paramétrico de Mann-Whitney para testar a veracidade da hipótese de que as medianas dos indicadores de alavancagem do conjunto total de empresas dos 48 países são estatisticamente iguais nos períodos Pré-Crise e Pós-Crise. Os resultados da Tabela 2 mostram que é possível rejeitar esta hipótese, com nível de confiança estatística de $95 \%$, para todos os seis indicadores de alavancagem.

Tabela 2 - Teste Não-Paramétrico de Mann-Whitney para os indicadores do conjunto total das empresas

\begin{tabular}{lcccccc}
\hline \hline & $\begin{array}{c}\text { Endivida- } \\
\text { mento } \\
\text { Oneroso }\end{array}$ & $\begin{array}{c}\text { Relação } \\
\text { Dívida/PL }\end{array}$ & $\begin{array}{c}\text { Endivida- } \\
\text { mento } \\
\text { Líquido 1 }\end{array}$ & $\begin{array}{c}\text { Endivida- } \\
\text { mento Líquido } \\
2\end{array}$ & $\begin{array}{c}\text { Endivida- } \\
\text { mento de } \\
\text { Longo Prazo }\end{array}$ & $\begin{array}{c}\text { Endivida- } \\
\text { mento a } \\
\text { Mercado }\end{array}$ \\
\hline \hline Mann-Whitney U & $3.591 \mathrm{E} 9$ & $3.552 \mathrm{E} 9$ & $3.319 \mathrm{E} 9$ & $3.589 \mathrm{E} 9$ & $3.651 \mathrm{E} 9$ & $3.382 \mathrm{E} 9$ \\
\hline Wilcoxon W & $8.572 \mathrm{E} 9$ & $8.533 \mathrm{E} 9$ & $6.031 \mathrm{E} 9$ & $6.300 \mathrm{E} 9$ & $8.632 \mathrm{E} 9$ & $6.094 \mathrm{E} 9$ \\
\hline Z & -8.172 & -11.949 & -34.986 & -8.398 & -2.393 & -28.445 \\
\hline $\begin{array}{l}\text { Asymp. Sig. } \\
\text { (2-tailed) }\end{array}$ & 0.000 & 0.000 & 0.000 & 0.000 & 0.017 & 0.000 \\
\hline \hline
\end{tabular}

Fonte: Elaboração própria

Os resultados dos testes apresentados na Tabela 2 mostram, portanto, que as medianas dos indicadores do nível de alavancagem financeira das empresas da amostra são diferentes, com significância estatística, nos períodos Pré-Crise e Pós-Crise. Isso fornece evidências de que houve alteração nas estruturas de capital das empresas em função do contexto da crise financeira internacional de 2008. A não aceitação da hipótese nula de que os níveis de endividamento das empresas no período anterior e posterior à crise de 2008 são iguais vai de encontro aos achados de alguns estudos anteriores, como por exemplo os realizados por Iqbal e Kume (2014) e Alves e Francisco (2015). Em outras palavras, os resultados apresentados na Tabela 2 sugerem indícios de que a crise financeira de 2008 alterou significativamente o grau de endividamento das empresas mundiais, o que corrobora os achados de Driffield e Pal (2010). 
Dado que uma crise financeira causa sérias restrições na oferta de crédito tanto por parte dos bancos quanto por parte do mercado de títulos de dívida (debêntures, bonds, eurobonds, export notes, commercial papers entre outros) era esperado que a crise de 2008 tivesse refletido na estrutura de capital das empresas ao redor de todo o mundo. Quando o mercado de crédito e de títulos de dívida privadas se contrai, as empresas tendem a buscar recursos externos no mercado de capitais, via emissão de novas ações por exemplo. Esse movimento tende a causar alterações significativas na estrutura de financiamento das firmas.

Um ponto que vale ser ressaltado, é a mudança observada no comportamento dos indicadores, que apresentavam, em média, uma tendência de redução na alavancagem até o ano da Crise. Com o advento desse período (2007-2008), a maioria dos indicadores apresentaram uma mudança no nível de alavancagem, com valores superiores ao do período Pré-Crise. Contudo, novamente foi observado a tendência de redução da alavancagem conforme há o afastamento temporal do epicentro da crise. Tal comportamento corrobora o apontado por Campello, Graham e Harvey (2010) em seu estudo, onde as empresas apresentaram comportamento condizente ao obtido em nossa amostra.

O que pode explicar esse comportamento acima destacado é o encarecimento do crédito nos períodos Pós-Crise. Como os credores tendem a ficar mais receosos nos períodos após uma crise financeira, os juros dos empréstimos bancários e as taxas de cupons exigidas pelos compradores de títulos de dívida tendem a ser elevados. A redução no volume de crédito e o aumento nas taxas de juros, tendem a levar as empresas a buscarem uma maior retenção de recursos internos nos períodos de crise. A retenção de lucros, via reduções nos volumes pagos na forma de dividendos aos acionistas, impacta diretamente na redução dos índices de endividamento das organizações, uma vez que acarreta elevações no patrimônio líquido das empresas (nas contas de reservas de lucros). Esses fatores, quando combinados ao longo dos anos após a crise, podem explicar a redução dos graus de alavancagem financeira constatada neste estudo.

A Tabela 3 apresenta as médias anuais dos indicadores de alavancagem calculados apenas para o conjunto das empresas localizadas nos países desenvolvidos.

Tabela 3 - Médias anuais dos indicadores de alavancagem para o conjunto das empresas dos países desenvolvidos

\begin{tabular}{lcccccc}
\hline \hline Conjunto das Empresas dos Países Desenvolvidos & & & \\
\hline Período & $\begin{array}{c}\text { Endivida- } \\
\text { mento } \\
\text { Oneroso }\end{array}$ & $\begin{array}{c}\text { Relação } \\
\text { Dívida/PL }\end{array}$ & $\begin{array}{c}\text { Endivida- } \\
\text { mento } \\
\text { Líquido } 1\end{array}$ & $\begin{array}{c}\text { Endivida- } \\
\text { mento } \\
\text { Líquido 2 }\end{array}$ & $\begin{array}{c}\text { Endivida- } \\
\text { mento de } \\
\text { Longo Prazo }\end{array}$ & $\begin{array}{c}\text { Endivida- } \\
\text { mento a } \\
\text { Mercado }\end{array}$ \\
\hline Pré-Crise & $\mathbf{0 . 2 6 0 5}$ & $\mathbf{0 . 7 0 2 3}$ & $\mathbf{0 . 2 7 4 9}$ & $\mathbf{0 . 2 5 1 3}$ & $\mathbf{0 . 5 6 4 2}$ & $\mathbf{0 . 3 0 9 9}$ \\
\hline 2002 & 0.2667 & 0.7203 & 0.2793 & 0.2573 & 0.5538 & 0.3643 \\
\hline 2003 & 0.2657 & 0.7259 & 0.2818 & 0.2573 & 0.5606 & 0.3437 \\
\hline 2004 & 0.2591 & 0.7015 & 0.2736 & 0.2518 & 0.5686 & 0.3071 \\
\hline 2005 & 0.2579 & 0.6939 & 0.2715 & 0.2475 & 0.5667 & 0.2849 \\
\hline 2006 & 0.2550 & 0.6782 & 0.2701 & 0.2452 & 0.5693 & 0.2651 \\
\hline Crise & $\mathbf{0 . 2 5 5 5}$ & $\mathbf{0 . 6 8 4 6}$ & $\mathbf{0 . 2 7 3 6}$ & $\mathbf{0 . 2 4 6 6}$ & $\mathbf{0 . 5 6 2 1}$ & $\mathbf{0 . 3 2 0 8}$ \\
\hline 2007 & 0.2551 & 0.6816 & 0.2722 & 0.2451 & 0.5682 & 0.2736 \\
\hline 2008 & 0.2558 & 0.6874 & 0.2749 & 0.2480 & 0.5563 & 0.3651 \\
\hline Pós-Crise & $\mathbf{0 . 2 5 4 0}$ & $\mathbf{0 . 6 6 7 9}$ & $\mathbf{0 . 2 7 4 8}$ & $\mathbf{0 . 2 4 7 8}$ & $\mathbf{0 . 5 7 2 0}$ & $\mathbf{0 . 3 2 6 9}$ \\
\hline 2009 & 0.2611 & 0.6837 & 0.2784 & 0.2526 & 0.5632 & 0.3489 \\
\hline 2010 & 0.2493 & 0.6601 & 0.2729 & 0.2465 & 0.5678 & 0.3179 \\
\hline 2011 & 0.2496 & 0.6608 & 0.2704 & 0.2447 & 0.5659 & 0.3319 \\
\hline 2012 & 0.2531 & 0.6672 & 0.2734 & 0.2462 & 0.5770 & 0.3290 \\
\hline 2013 & 0.2571 & 0.6680 & 0.2781 & 0.2492 & 0.5861 & 0.3075 \\
\hline Média Geral & $\mathbf{0 . 2 5 6 6}$ & $\mathbf{0 . 6 8 3 4}$ & $\mathbf{0 . 2 7 4 6}$ & $\mathbf{0 . 2 4 8 8}$ & $\mathbf{0 . 5 6 7 4}$ & $\mathbf{0 . 3 1 9 9}$ \\
\hline \hline
\end{tabular}

Fonte: Elaboração própria 
Aplicado o Teste de Normalidade de Kolgomorov-Smirnov, com nível de confiança estatística de 95\%, a hipótese de normalidade da distribuição das séries de indicadores de alavancagem para os países desenvolvidos foi rejeitada para todos os indicadores, a exemplo do observado para todos os países. Assim, foi aplicado o Teste Não-Paramétrico de MannWhitney para testar a veracidade da hipótese nula de que as medianas dos indicadores de alavancagem das empresas dos países desenvolvidos são estatisticamente iguais nos períodos Pré-Crise e Pós-Crise.

Os resultados da Tabela 4 mostram que é possível rejeitar esta hipótese, com nível de confiança estatística de $95 \%$, para cinco dos seis indicadores de alavancagem. A exceção foi o indicador Endividamento Líquido 2.

Tabela 4 - Teste Não-Paramétrico de Mann-Whitney para os indicadores das empresas dos países desenvolvidos

\begin{tabular}{lcccccc}
\hline \hline Empresas dos Países Desenvolvidos & $\begin{array}{c}\text { Endivida- } \\
\text { mento } \\
\text { Oneroso }\end{array}$ & $\begin{array}{c}\text { Relação } \\
\text { Dívida/PL }\end{array}$ & $\begin{array}{c}\text { Endivida-mento } \\
\text { Líquido 1 }\end{array}$ & $\begin{array}{c}\text { Endivida-mento } \\
\text { Líquido 2 }\end{array}$ & $\begin{array}{c}\text { Endivida- } \\
\text { mento de } \\
\text { Longo Prazo }\end{array}$ & $\begin{array}{c}\text { Endivida- } \\
\text { mento a } \\
\text { Mercado }\end{array}$ \\
\hline Mann-Whitney U & $9.515 \mathrm{E} 8$ & $9.292 \mathrm{E} 8$ & $8.814 \mathrm{E} 8$ & $9.768 \mathrm{E} 8$ & $9.660 \mathrm{E} 8$ & $8.804 \mathrm{E} 8$ \\
\hline Wilcoxon W & $2.181 \mathrm{E} 9$ & $2.159 \mathrm{E} 9$ & $1.659 \mathrm{E} 9$ & $2.206 \mathrm{E} 9$ & $1.743 \mathrm{E} 9$ & $1.658 \mathrm{E} 9$ \\
\hline Z & -6.864 & -12.726 & -25.586 & -0.223 & -3.068 & -25.536 \\
\hline $\begin{array}{l}\text { Asymp. Sig. } \\
\text { (2-tailed) }\end{array}$ & 0.000 & 0.000 & 0.000 & 0.823 & 0.002 & 0.000 \\
\hline \hline
\end{tabular}

Fonte: Elaboração própria

Os resultados da Tabela 4 revelam que a crise financeira impactou o nível de alavancagem das empresas dos países desenvolvidos. Os números do Teste de Mann-Whitney mostram que as medianas dos indicadores de alavancagem são diferentes, com significância estatística, entre os períodos Pré-Crise e Pós-Crise. Somente o indicador Endividamento Líquido 2 contrariou essa observação geral, dado que apresentou a mesma mediana entre os períodos analisados. Este resultado conduz à ideia de que a variável Fluxo de Caixa (que é captada somente por este indicador e não pelos outros) do período apresentou uma variação significativa média contrária ao valor do passivo financeiro. Em outras palavras, especificamente para o caso desse indicador, o fluxo de caixa gerado pela empresa pode ter atuado de forma a equilibrar o valor do passivo financeiro (o decréscimo de um implicou no acréscimo de outro), fazendo com que não se detectassem diferenças para esse indicador entre os períodos pré e pós-crise.

Um importante destaque a se fazer com relação aos dados apresentados na Tabela 4 refere-se ao comportamento do indicador Endividamento a Mercado. Como pode ser observado na Tabela 4, esse indicador apresentou uma média de 30,99\% nos cinco anos anteriores à crise (2006-2006), passando para 32,08\% no auge da crise (2007-2008) e aumentando para 32,69\% para a média dos cinco anos posteriores à crise (2009-2013). Esse comportamento também foi observado na Tabela 1. Observa-se que o aumento desse indicador no decorrer dos anos estudados destoa do comportamento dos demais índices deste estudo. Uma possível explicação para essa observação, deve-se ao fato de que esse indicador incorpora, no seu denominador, o valor de mercado da empresa. Com isso, uma redução no valor de mercado da firma implica numa elevação desse indicador. Em outras palavras, o indicador Endividamento a Mercado foi aumentando na medida em que o valor de mercado das empresas foi diminuindo. A redução 
O impacto da crise financeira internacional de 2008 sobre a estrutura de capital das empresas de países desenvolvidos e emergentes

nos valores de mercado das empresas, tanto nas economias desenvolvidas como nos países em desenvolvimento, deve-se à queda brusca no preço das ações dessas companhias.

A Tabela 5, por sua vez, apresenta as médias anuais dos indicadores de alavancagem calculados apenas para o conjunto das empresas dos países em desenvolvimento.

Tabela 5 - Médias anuais dos indicadores de alavancagem para os indicadores do conjunto das empresas dos países em desenvolvimento

\begin{tabular}{lcccccc}
\hline \hline Conjunto das Empresas dos Países Em desenvolvimento & & \\
\hline \hline Período & $\begin{array}{c}\text { Endivida- } \\
\text { mento } \\
\text { Oneroso }\end{array}$ & $\begin{array}{c}\text { Relação } \\
\text { Dívida/PL }\end{array}$ & $\begin{array}{c}\text { Endivida- } \\
\text { mento } \\
\text { Líquido 1 }\end{array}$ & $\begin{array}{c}\text { Endivida- } \\
\text { mento } \\
\text { Líquido 2 }\end{array}$ & $\begin{array}{c}\text { Endivida- } \\
\text { mento de } \\
\text { Longo Prazo }\end{array}$ & $\begin{array}{c}\text { Endivida- } \\
\text { mento a } \\
\text { Mercado }\end{array}$ \\
\hline Pré-Crise & $\mathbf{0 . 2 6 9 7}$ & $\mathbf{0 . 6 7 9 6}$ & $\mathbf{0 . 2 8 5 2}$ & $\mathbf{0 . 2 5 3 1}$ & $\mathbf{0 . 4 4 2 5}$ & $\mathbf{0 . 3 0 8 6}$ \\
\hline 2002 & 0.2607 & 0.6305 & 0.2766 & 0.2488 & 0.4291 & 0.3186 \\
\hline 2003 & 0.2697 & 0.6655 & 0.2840 & 0.2530 & 0.4279 & 0.3052 \\
\hline 2004 & 0.2696 & 0.6783 & 0.2846 & 0.2547 & 0.4388 & 0.3054 \\
\hline 2005 & 0.2681 & 0.6832 & 0.2823 & 0.2499 & 0.4485 & 0.3200 \\
\hline 2006 & 0.2769 & 0.7179 & 0.2938 & 0.2572 & 0.4582 & 0.2976 \\
\hline Crise & $\mathbf{0 . 2 7 0 4}$ & $\mathbf{0 . 7 0 0 1}$ & $\mathbf{0 . 2 9 1 7}$ & $\mathbf{0 . 2 5 4 5}$ & $\mathbf{0 . 4 5 2 0}$ & $\mathbf{0 . 3 1 5 1}$ \\
\hline 2007 & 0.2721 & 0.7073 & 0.2930 & 0.2547 & 0.4566 & 0.2694 \\
\hline 2008 & 0.2688 & 0.6935 & 0.2905 & 0.2544 & 0.4476 & 0.3569 \\
\hline Pós-Crise & $\mathbf{0 . 2 6 2 4}$ & $\mathbf{0 . 6 6 6 1}$ & $\mathbf{0 . 2 8 3 8}$ & $\mathbf{0 . 2 5 1 0}$ & $\mathbf{0 . 4 5 5 8}$ & $\mathbf{0 . 3 1 4 1}$ \\
\hline 2009 & 0.2655 & 0.6715 & 0.2841 & 0.2524 & 0.4611 & 0.3191 \\
\hline 2010 & 0.2601 & 0.6653 & 0.2841 & 0.2491 & 0.4667 & 0.2816 \\
\hline 2011 & 0.2600 & 0.6654 & 0.2840 & 0.2486 & 0.4533 & 0.3218 \\
\hline 2012 & 0.2627 & 0.6632 & 0.2839 & 0.2515 & 0.4447 & 0.3262 \\
\hline 2013 & 0.2639 & 0.6651 & 0.2833 & 0.2533 & 0.4538 & 0.3194 \\
\hline Média Geral & $\mathbf{0 . 2 6 6 3}$ & $\mathbf{0 . 6 7 6 8}$ & $\mathbf{0 . 2 8 5 6}$ & $\mathbf{0 . 2 5 2 3}$ & $\mathbf{0 . 4 5 0 7}$ & $\mathbf{0 . 3 1 2 5}$ \\
\hline \hline
\end{tabular}

Fonte: Elaboração própria

Novamente, ao aplicar o Teste de Normalidade de Kolgomorov-Smirnov, com nível de confiança estatística de $95 \%$, a hipótese de normalidade da distribuição das séries de indicadores de alavancagem foi rejeitada para todos os indicadores do estudo. Por isso, foi aplicado posteriormente o Teste Não-Paramétrico de Mann-Whitney com intuito de testar a veracidade da hipótese de nulidade de que as medianas dos indicadores de alavancagem das empresas dos países em desenvolvimento são estatisticamente iguais nos períodos Pré-Crise e Pós-Crise. Os resultados da Tabela 6 mostram que é possível rejeitar esta hipótese, com nível de confiança estatística de 95\%, para todos os seis indicadores de alavancagem.

Tabela 6 - Teste Não-Paramétrico de Mann-Whitney para os indicadores do conjunto das empresas dos países em desenvolvimento

\begin{tabular}{lcccccc}
\hline \hline Empresas dos Países Em desenvolvimento & & & & \\
\hline \hline & $\begin{array}{c}\text { Endivida- } \\
\text { mento } \\
\text { Oneroso }\end{array}$ & $\begin{array}{c}\text { Relação } \\
\text { Dívida/PL }\end{array}$ & $\begin{array}{c}\text { Endivida-mento } \\
\text { Líquido 1 }\end{array}$ & $\begin{array}{c}\text { Endivida-mento } \\
\text { Líquido 2 }\end{array}$ & $\begin{array}{c}\text { Endivida- } \\
\text { mento de } \\
\text { Longo Prazo }\end{array}$ & $\begin{array}{c}\text { Endivida- } \\
\text { mento a } \\
\text { Mercado }\end{array}$ \\
\hline Mann-Whitney U & $3.591 \mathrm{E} 9$ & $3.552 \mathrm{E} 9$ & $3.319 \mathrm{E} 9$ & $3.589 \mathrm{E} 9$ & $3.651 \mathrm{E} 9$ & $3.382 \mathrm{E} 9$ \\
\hline Wilcoxon W & $8.572 \mathrm{E} 9$ & $8.533 \mathrm{E} 9$ & $6.031 \mathrm{E} 9$ & $6.300 \mathrm{E} 9$ & $8.632 \mathrm{E} 9$ & $6.094 \mathrm{E} 9$ \\
\hline Z & -8.172 & -11.949 & -34.986 & -8.398 & -2.393 & -28.445 \\
\hline $\begin{array}{l}\text { Asymp. Sig. } \\
\text { (2-tailed) }\end{array}$ & 0.000 & 0.000 & 0.000 & 0.000 & 0.017 & 0.000 \\
\hline \hline
\end{tabular}

Fonte: Elaboração própria 
Os resultados do Teste de Mann-Whitney revelam que as medianas dos indicadores de alavancagem são diferentes, com significância estatística, nos períodos Pré-Crise e Pós-Crise, quando considerado o conjunto das empresas dos países em desenvolvimento, o que significa que houve alteração nas estruturas de capital das empresas em função do contexto da crise financeira internacional de 2008, a exemplo do observado anteriormente para os países desenvolvidos.

A constatação de que os níveis de endividamento das empresas situadas em países desenvolvidos e em desenvolvimento comportaram-se de maneira similar nos períodos anteriores e posteriores à crise corroboram os achados de algumas pesquisas realizadas em períodos anteriores ao deste estudo (2002 à 2013), como por exemplo Booth et al. (2001). Esses achados fornecem indícios de que a crise financeira de 2008 afetou de maneira parecida as decisões sobre a estrutura de capital das 29.803 empresas dos 48 países analisados nesta pesquisa. A magnitude e a velocidade de transmissão da crise de 2008 , assim como a redução global na oferta de crédito e a elevação das taxas de juros em todo o mundo, podem explicar essa constatação.

As análises com base nas medianas dos indicadores de alavancagem considerados mostraram que há diferenças estatisticamente significantes entre os períodos Pré-Crise e PósCrise. De forma geral, ao se analisar a evolução dos indicadores médios de endividamento apresentados na Tabela 5, observa-se que houve, na média, uma tendência de redução nos níveis de alavancagem financeira das empresas situadas nos países em desenvolvimento nos períodos de 2002 à 2013. Mais uma vez, o indicador Endividamento a Mercado revelou uma variação crescente (aumento) significativa entre os períodos pré e pós-crise, assim como observado anteriormente para os outros dois conjuntos de empresas. Como dito anteriormente, o Endividamento a Mercado é um indicador que tem o valor de mercado da empresa como componente do denominador da razão que o determina. No período pós-crise os valores de mercado das empresas estavam bastante deteriorados, o que contribui para reduzir consideravelmente os níveis do Endividamento a Mercado.

Em outro destaque, a razão para o declínio relevante do indicador Relação Dívida/PL se deve ao fato de que a crise financeira internacional de 2008 foi uma das maiores crises deflagradas desde a Grande Depressão de 1929, com impacto direto na liquidez de crédito do sistema como um todo. Os recursos financeiros se tornaram escassos e mais caros, o que limitou o nível de endividamento das empresas no período pós-crise. Em outras palavras, como o numerador do indicador Relação Dívida/PL é, em grande parte, composto pelas dívidas onerosas captadas juntos às instituições do mercado financeiro, uma retração na oferta de crédito por parte dos Bancos, leva a uma redução da alavancagem empresarial mensurada por este indicador.

Como forma de permitir uma melhor visualização do comportamento das principais variáveis que compuseram os indicadores de endividamento selecionados para esta pesquisa, assim como os resultados obtidos ao longo do tempo de análise desse estudo, foi construído o Gráfico 1.

O Gráfico 1 ilustra as explicações dadas para o comportamento do Endividamento a Mercado e do indicador Relação Dívida/PL dadas nos parágrafos anteriores. O gráfico mostra, para o período entre os anos de 2002 e 2013, a variação percentual do valor de mercado das empresas, do passivo financeiro e do indicador Endividamento a Mercado. Mostra também o comportamento dos valores absolutos médios do valor de mercado e do passivo financeiro das empresas, para o mesmo período. No gráfico, é possível notar claramente a inclinação ascendente do valor das empresas até 2007 e o impacto da crise (declínio) sobre esta variável a partir de 2008. Efeito semelhante ocorreu com o endividamento das empresas. 
O impacto da crise financeira internacional de 2008 sobre a estrutura de capital das empresas de países desenvolvidos e emergentes

Gráfico 1 - Comportamento do Endividamento a Mercado, Valor de Mercado e Passivo Financeiro das empresas

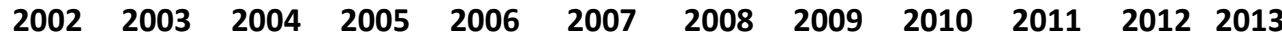

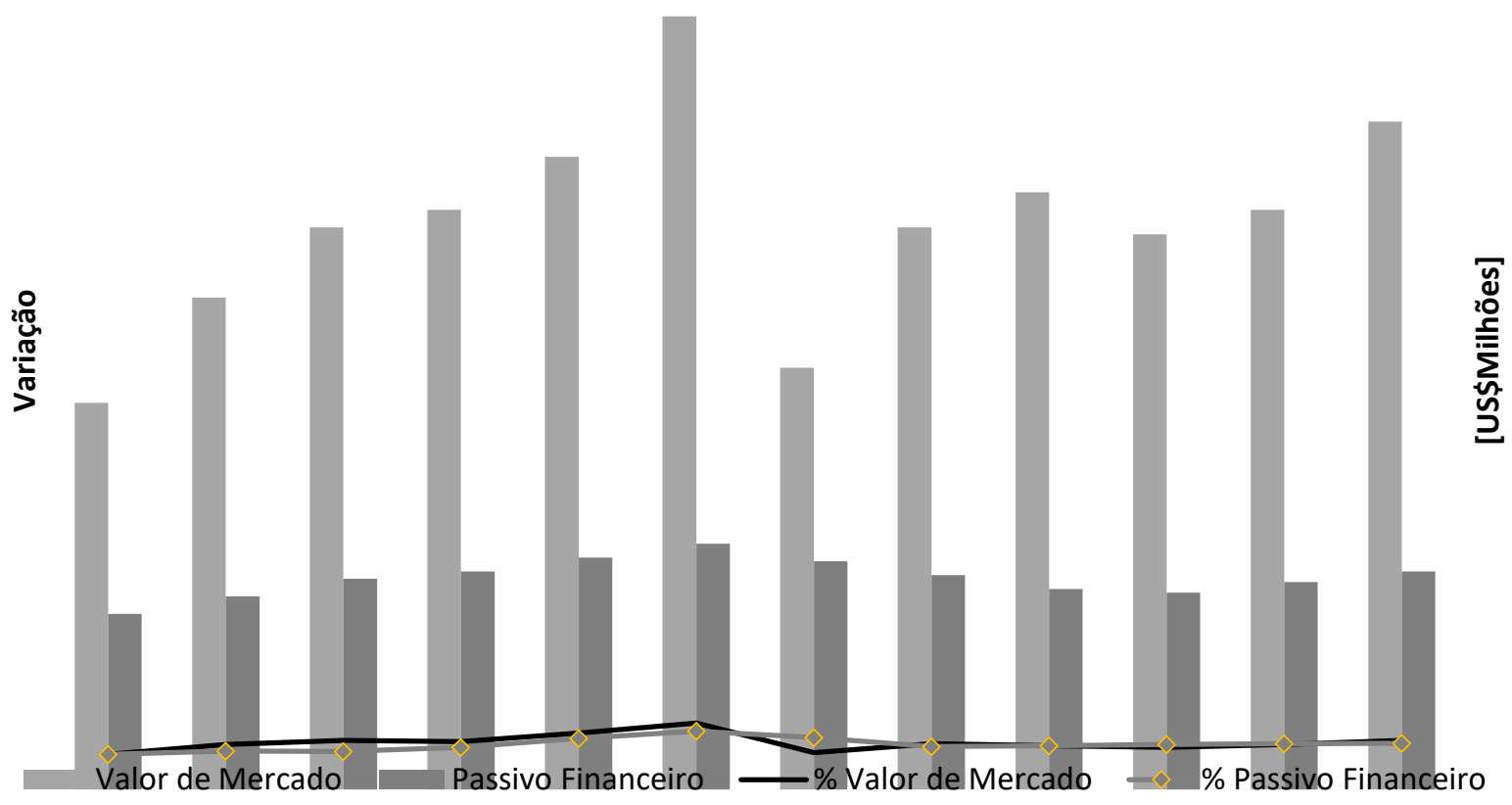

Fonte: Elaboração própria

Em suma, os achados dessa pesquisa revelam o impacto causado pela drástica retração no mercado de crédito mundial na estrutura de capital das empresas em todo o mundo após a deflagração da crise americana dos empréstimos hipotecários subprimes de 2008 . O desequilíbrio geral na oferta e no encarecimento do crédito, impactou na redução dos níveis de endividamento das companhias, independentemente do nível de desenvolvimento do seu país de origem, resultado da intensificação do processo de globalização das últimas décadas. As consequências dessa crise ainda se fazem sentir no ambiente empresarial de todo o mundo. A dificuldade no acesso ao crédito levou a uma redução dos investimentos empresariais, contribuindo para a queda da atividade econômica e elevação dos níveis de desemprego em todo o mundo.

\section{Considerações Finais}

O objetivo deste estudo foi investigar se a crise financeira internacional de 2008 causou impactos sobre a estrutura de capital das empresas em todo o mundo. Utilizando um espaço amostral de 29.803 empresas de 48 países diferentes, foram detectadas alterações no nível de alavancagem, medido por seis indicadores, entre os períodos pré e pós-crise. A análise foi feita para três grandes grupos de empresas: o conjunto total das empresas; o conjunto das empresas situadas em países desenvolvidos; e o conjunto das empresas situadas em países em desenvolvimento.

Os resultados permitiram concluir que a crise efetivamente impactou no nível de alavancagem das empresas, com sua efetiva redução no período imediatamente posterior à crise, comportamento este observado para os três grupos analisados. Foi possível concluir também, 
com base nos resultados do Teste de Mann-Whitney, que as medianas dos indicadores de alavancagem são diferentes para o conjunto total de empresas dos 48 países, com significância estatística, entre os períodos Pré-Crise e Pós-Crise, sugerindo indícios de que houve alteração nas estruturas de capital das empresas em função do contexto da crise financeira internacional de 2008. Mais especificamente, o indicador Relação Dívida/PL revelou uma redução significativa entre os períodos pré e pós-crise para os três conjuntos de empresas, e o indicador Endividamento a Mercado revelou um aumento expressivo. Estas alterações se devem ao impacto da crise na liquidez de crédito do sistema financeiro internacional, que limitou a capacidade de endividamento das empresas no período pós-crise, e à redução drástica do valor das empresas.

De uma maneira geral, foi possível detectar uma alteração na estrutura de capital das empresas entre os períodos pré e pós-crise financeira internacional de 2008, expressa pela redução dos indicadores de alavancagem, e não houve diferenças relevantes destes efeitos entre as empresas, quando considerada sua localização em países desenvolvidos e em desenvolvimento.

Estes resultados são compatíveis com os de Driffield e Pal (2010) que verificaram alterações na estrutura de capital de empresas do Leste Asiático, em um período anterior e posterior à Crise Asiática de 1997. Também são aderentes aos resultados obtidos por DemirgüçKunt e Maksimovic (1998) e por Mokhova e Zinecker (2014) que mostraram que as condições macroeconômicas têm um importante papel na determinação da estrutura de capital das empresas.

No tocante às diferenças geradas pela localização das empresas em países desenvolvidos e em desenvolvimento, a conclusão obtida se alinha com a de Booth et al. (2001) que concluiu que os níveis de alavancagem não eram significativamente distintos dentre as empresas de ambos os grupos de países e que a nacionalidade da empresa não estava relacionada a uma determinada forma de estrutura de capital.

Contudo, as conclusões do estudo não são compatíveis com as de Kayo e Kimura (2011) que encontraram evidências de que os fatores mais importantes para a determinação da estrutura de capital são relacionados à variação da estrutura no tempo e nas características específicas da empresa (lucratividade e tamanho) em detrimento de características ou da situação macroeconômica dos países. Também não se alinham as obtidas no estudo de Lemmon, Roberts e Zender (2008) que encontraram evidências de que as companhias tendem a manter suas decisões de alavancagem estáveis ao longo do tempo, mesmo com a ocorrência de crises.

\section{Referências}

ADRIAN, Tobias; FLEMING, Michael; SHACHAR, Or.; VOGT, Erik. Market Liquidity after the Financial Crisis. Federal Reserve Bank of New York, Staff Report No. 796. October

2016. Revised June 2017.2 Disponível em:
https://www.newyorkfed.org/medialibrary/media/research/staff_reports/sr796.pdf. Acesso em: 01/09/2017.

ALVES, Paulo; FRANCISCO, Paulo. The impact of institutional environment on the capital structure of firms during recent financial crises. The Quarterly Review of Economics and Finance, v. 57, p. 129-146, 2015. https://doi.org/10.1016/j.qref.2014.12.001 
ARIFF, Mohamed; TAUFIQ, Hassan; SHAMSHER, Mohamad. How capital structure adjusts dynamically during financial crises. Corporate Finance Review, v. 13, n 3, p. 11-24, 2008.

BHAMRA, Harjoat S.; KUEHN, Lars-Alexander; STREBULAEV, Ilya A. The aggregate dynamics of capital structure and macroeconomic risk. Review of Financial Studies, v. 23, n. 12, p. 4187-4241, 2010. https://doi.org/10.1093/rfs/hhq075

BIS - Bank for International Settlements. 79th Annual Report. Basel: BIS, 2009.

BIS - Bank for International Settlements. 80th Annual Report. Basel: BIS, 2010.

BOOTH, Laurence; AIVAZIAN, Varouj; DEMIRGUC-KUNT, Asli; MAKSIMOVIC, Vojislav. Capital structure in developing countries. The Journal of Finance, v. 56, n. 1, p. 87130, 2001. https://doi.org/10.1111/0022-1082.00320

CARVALHAL, Andre; LEAL, Ricardo Pereira Câmara. The world financial crisis and the international financing of Brazilian companies. BAR-Brazilian Administration Review, v. 10, n. 1, p. 18-39, 2013. http://dx.doi.org/10.1590/S1807-76922012005000007

CAMPELLO, Murillo; GRAHAM, John R.; HARVEY, Campbell R. The real effects of financial constraints: evidence from a financial crisis. Journal of Financial Economics, v. 97, p. 470-487, 2010. https://doi.org/10.1016/j.jfineco.2010.02.009

DANG, Viet Anh; KIM, Mimjoo; SHIN, Yongheol. Asymetric adjustment toward optimal capital structure: evidence from a crisis. International Review of Financial Analysis, v. 33, p. 226-242, 2014. https://doi.org/10.1016/j.irfa.2014.02.013

DAS, A.; DAS, S. S.; LIM, E. N. K. Diversification strategy, capital structure, and the Asian financial crisis (1997-1998): evidence from Singapore firms. Strategic Management Journal, v. 30, p. 577-594, 2009. https://doi.org/10.1002/smj.752

DEMIRGÜÇ-KUNT, A.; MAKSIMOVIC, V. Law, finance and firm growth. The Journal of Finance, v. 53, n. 6, p. 2107-2137, 1998. https://doi.org/10.1111/0022-1082.00084

DRIFFIELD, Nigel; PAL, Sarmistha. Evolution of capital structure in east Asia: corporate inertia or endeavours? Journal of the Royal Statistical Society, v. 173, n. 1, p. 1-29, 2010. https://doi.org/10.1111/j.1467-985X.2009.00603.x

FLANNERY, Mark J.; RANGAN, Kasturi P. Partial adjustment toward target capital structures. Journal of Financial Economics, v. 79, p. 469-506, 2006. https://doi.org/10.1016/j.jfineco.2005.03.004

GARCIA-APPENDINI, Emilia; MONTORIOL-GARRIGA, Judit. Firms as liquidity providers: evidence from the 2007-2008. Journal of Financial Economics, v. 109, p. 272291, 2013. https://doi.org/10.1016/j.jfineco.2013.02.010

GIL, Antonio Carlos. Como elaborar projetos de pesquisa. 4. ed. São Paulo: Atlas, 2002. 175 p. 
HARRISON, Barry; WIDJAJA, Theodorus Wisnu. The Determinants of Capital Structure: Comparison between Before and After Financial Crisis. Economic Issues, v. 19, n. 2, p. 55-82, 2014.

IMF - International Monetary Fund. Annual Report. Washington, DC: IMF, 2009.

IMF - International Monetary Fund. World Economic Outlook. Washington, DC: IMF, 2015.

IQBAL, Abdullah.; KUME, Ortenca. Impact of Financial Crisis on Firms' Capital Structure in UK, France, and Germany. Multinational Finance Journal, v. 18, n. 3/4, p. 249-280, 2014.

KAHLE, Kathleen M.; STULZ, René M. Access to capital, investment, and the financial crisis. Journal of Financial Economics, v. 110, n. 2, p. 280-299. 2013. https://doi.org/10.1016/j.jfineco.2013.02.014

KAYO, Eduardo Kazuo; KIMURA, Herbert. Hierarchical determinants of capital structure. $\begin{array}{llllllll}\text { Journal of Banking } \& \text { Finance, } & \text { v. } & 35, & \text { p. } & 358-371,\end{array}$ https://doi.org/10.1016/j.jbankfin.2010.08.015

LEMMON, M. L.; ROBERTS, M. R.; ZENDER, J. F. Back to the beginning: persistence and the cross-section of corporate capital structure. The Journal of Finance, v. 63, n. 4, p. 15751608, 2008. https://doi.org/10.1111/j.1540-6261.2008.01369.x

MODIGLIANI, Franco; MILLER, Merton H. The cost of capital, corporation finance and the theory of investment. The American Economic Review, v. 48, n. 3, p. 261-297, 1958.

MODIGLIANI, Franco; MILLER, Merton H. Corporate income taxes and the cost of capital: a correction. The American Economic Review, v. 53, n. 3, p. 433-443, 1963.

MOKHOVA, Natalia; ZINECKER, Marek. Macroeconomic factors and corporate capital structure. Procedia - Social and Behavioral Sciences, v. 110, p. 530-540, 2014. https://doi.org/10.1016/j.sbspro.2013.12.897

RAJAN, Raghuram G.; ZINGALES, Luigi. What do we know about capital structure? Some evidence from international data. The Journal of Finance, v. 50, n. 5, p. 1421-1460, 1995. https://doi.org/10.1111/j.1540-6261.1995.tb05184.x

RICHARDSON, Roberto Jarry. Pesquisa Social: métodos e técnicas. São Paulo: Atlas, 1999. $334 \mathrm{p}$.

UNCTAD - United Nations. The financial and economic crisis of 2008-2009 and developing countries. New York: United Nations, 2010.

WOLF, Martin. As transições e os choques: o que aprendemos - e o que ainda temos que aprender - com a crise financeira. São Paulo: Companhia das Letras, 2015.

* Uma versão previa deste artigo foi apresentada no XVIII SEMEAD - Seminários em Administração, 2015. 